\title{
Comparison of two twice-daily doses of budesonide/formoterol maintenance and
} reliever therapy

\author{
M. Aubier*, R. Buhl\# , T. Ekström ${ }^{\top}$, J. Ostinelli', C.P. van Schayck ${ }^{\S, f}$, \\ O.Selroos** and J. Haughney ${ }^{\# \#}$
}

ABSTRACT: The aim of this study was to compare two budesonide/formoterol maintenance doses within the budesonide/formoterol maintenance and reliever therapy concept and to identify possible patient characteristics at baseline which would predict a better response to a higher than standard maintenance dose.

A total of $\mathbf{8 , 4 2 4}$ patients with symptomatic asthma when using an inhaled corticosteroid (ICS) with or without a long-acting $\beta_{2}$-agonist were randomised to budesonide/formoterol $160 / 4.5 \mu \mathrm{g}$, one $(1 \times 2)$ or two $(2 \times 2)$ inhalations b.i.d. Patients used the same inhaler as needed for symptom relief. The primary outcome variable was time to first severe asthma exacerbation.

In the total study population, the time to first severe asthma exacerbation was prolonged by $18 \%$ with $2 \times 2$ versus $1 \times 2$ (hazard ratio $0.82 ; p=0.03$ ). Lung function (peak expiratory flow) was the only statistically significant predictor of a better response to $2 \times 2$. The mean daily ICS doses were 737 and $463 \mu \mathrm{g}$ in the $2 \times 2$ and $1 \times 2$ groups, respectively.

In a real-life setting, budesonide/formoterol maintenance and reliever therapy at the $\mathbf{2} \times \mathbf{2}$ maintenance dose did prolong time to first severe exacerbation but at a higher medication load. Patients with low lung function benefited most from the higher maintenance dose.

KEYWORDS: Asthma, budesonide/formoterol, exacerbations, maintenance and reliever therapy, predictive factors, Symbicort SMART

B udesonide/formoterol (Symbicort ${ }_{\circledast}$ Turbuhaler®, AstraZeneca; the Symbicort dry powder formulation Turbuhaler is not currently approved in the USA) maintenance and reliever therapy (Symbicort SMART ${ }_{\circledR}$, AstraZeneca; the Symbicort SMART posology is currently not approved in the USA) is established as a useful treatment for appropriate patients with asthma $[1,2]$. In clinical studies, this treatment concept has consistently shown a reduction in the rate of asthma exacerbations compared with higher doses of budesonide [3-5] or fluticasone [6]. Superiority of budesonide/formoterol maintenance and reliever therapy has also been demonstrated versus the same [7] or higher [8] maintenance doses of budesonide/formoterol or salmeterol/fluticasone [8-10] with a short-acting $\beta_{2}$-agonist (SABA) [7-10] or formoterol [7] as reliever. In addition, preventing exacerbations using this concept has been achieved at a lower total corticosteroid load [1, 2].

When using fixed inhaled corticosteroid (ICS)/ long-acting $\beta_{2}$-agonist (LABA) regimens, the choice of steroid maintenance dose for the individual patient will depend on asthma severity, similarly to ICS monotherapy. A recent study using fluticasone/salmeterol for maintenance treatment and SABA for symptom relief showed that $25 \%$ of the patients, who did not obtain control on the starting ICS dose level, achieved control when the ICS dose was doubled [11]. When prescribing budesonide/formoterol as both maintenance and reliever therapy, patients will inhale additional ICS doses when symptoms appear, which may allow for a lower maintenance dose without loss of efficacy.

In previous budesonide/formoterol maintenance and reliever trials, one or two maintenance doses were given twice daily. A study with a one dose once daily maintenance regimen plus additional doses as needed showed less asthma control days compared to one dose twice daily [12]. Therefore, two doses per day is considered the lowest recommended maintenance dose within the budesonide/formoterol maintenance and reliever therapy concept. However, there are no comparative studies

\section{AFFILIATIONS}

${ }^{*}$ Dept of Pneumology A, Hôpital Bichat, Assistance Publique Hôpitaux de Paris, Inserm U700 Faculté de Médecine Denis Diderot, Paris, and ${ }^{+}$Medical Dept, AstraZeneca, Rueil Malmaison, France.

\#Pulmonary Dept, Mainz University Hospital, Mainz, Germany.

"Medical Dept, AstraZeneca,

Södertälje, and

**Semeco, Vejbystrand, Sweden.

${ }^{\S}$ Maastricht University/CAPHRI,

Maastricht, The Netherlands.

${ }^{f}$ Dept of General Practice, University

of Edinburgh, Edinburgh, and

\#\#Academic Primary Care,

University of Aberdeen, Aberdeen, UK.

\section{CORRESPONDENCE}

M. Aubier

Service de Pneumologie A

Hôpital Bichat

46 rue Henri Huchard

75018 Paris

France

E-mail: michel.aubier@bch.aphp.fr

Received:

Feb 092010

Accepted after revision:

June 042010

First published online:

July 012010 
to date evaluating the potential benefit of increasing the maintenance dose from two to four inhalations per day.

The aim of this study was, therefore, to evaluate the impact of doubling the maintenance dose of the budesonide/formoterol maintenance and reliever therapy concept by comparing a standard dose, $160 / 4.5 \mu \mathrm{g}$, one inhalation b.i.d. plus as-needed, with the highest recommended maintenance dose, 160/4.5 $\mu \mathrm{g}$, two inhalations b.i.d. plus as-needed. Furthermore, analyses were planned to identify baseline patient characteristics that would predict a better response to the higher maintenance dose in terms of the primary outcome measure, time to first severe asthma exacerbation. A data collection plan to enable this was developed prospectively.

\section{METHODS}

\section{Study design and patients}

This was an open, randomised, parallel-group, 6-month multicentre study in patients with moderate-to-severe asthma who were symptomatic despite daily use of an ICS with or without LABA. Patients should be $\geqslant 18$ yrs of age and have a $\geqslant 6$-month documented history of asthma according to the American Thoracic Society guidelines [13]. Patients were required to be symptomatic, as indicated by a history of SABA use for symptom relief during the previous month, despite ICS (with or without LABA maintenance therapy) for $\geqslant 1$ month at a constant daily dose of $\geqslant 500 \mu \mathrm{g}$ beclomethasone dipropionate, or other ICS at equivalent doses.

The study started with a 2-week run-in period when patients continued their current asthma maintenance treatment and used terbutaline (Bricanyl ${ }_{\circledR}$ Turbuhaler ${ }_{\circledR}$; AstraZeneca, Södertälje, Sweden) as reliever medication.

To be randomised, patients treated with ICS and no LABA should have used at least one terbutaline inhalation for symptom relief on $\geqslant 4$ of the last 7 days of the run-in period and those treated with both ICS and LABA should have used as-needed terbutaline for symptom relief on $\geqslant 2$ of the last 7 days of the run-in period. No change in asthma maintenance treatment was allowed during run-in and patients with exacerbations during run-in were excluded.

Study entry criteria were broad to reflect the real-life situation. No withdrawal of SABA or LABA was requested before the reversibility test. Smokers could be enrolled, but not those $>40$ yrs of age with a smoking history of $\geqslant 10$ pack-yrs, nor people with a diagnosis of chronic obstructive pulmonary disease. After the run-in period, eligible patients were randomly allocated to one of the following two treatments; budesonide/formoterol (Symbicort Turbuhaler ${ }^{\circledR}$, AstraZeneca) $160 / 4.5 \mu \mathrm{g}$ b.i.d. $(1 \times 2)$ or $2 \times 160 / 4.5 \mu \mathrm{g}$ b.i.d. $(2 \times 2)$. By the definition of the treatment concept, budesonide/formoterol was also used as reliever medication.

Randomisation was performed via an interactive web response system developed by AstraZeneca, Lund, Sweden. There were four visits in the study, the first before and the second after the 2-week run-in period (visit 1 and 2), one after 3 months of treatment (visit 3) and the last after 6 months of treatment (visit 4).

The first patient entered the study in March 2007 and the last patient completed the study in December 2008.

\section{Assessments}

Demographic, lifestyle and clinical data were collected at baseline. During the 2-week run-in period and during 2-week periods prior to visits 3 and 4, patients recorded in a notebook the number of inhalations taken as maintenance medication, the number of reliever inhalations used, asthma symptoms (yes/no) and night-time awakenings (yes/no) due to asthma. At randomisation (visit 2) and at the end of the study (visit 4), lung function assessments were performed; peak expiratory flow (PEF) and, if available (due to the real-life setting of the study), spirometry (forced expiratory volume in $1 \mathrm{~s}$; FEV1).

The five-question Asthma Control Questionnaire (ACQ-5) [14, 15] excluding FEV1 (as FEV1 was not measured at all clinics) and use of SABA (as budesonide/formoterol should be used as reliever medication) was completed via self-administration at visits 2, 3 and 4. The scale of each ACQ-5 component is 0-6, with 0 as the best. The ACQ-5 total scores were reported in three groups: mean scores $<0.75$ (well controlled asthma), 0.75-1.5 (intermediate) and $>1.5$ (poorly controlled asthma). These intervals were based on data from a previous large clinical study [16].

The primary variable of efficacy was time to first severe asthma exacerbation, defined as deterioration in asthma leading to a need for oral or systemic corticosteroids either for $\geqslant 3$ days, and/or associated with hospitalisation, an emergency room visit or other patient-initiated unscheduled visits to a healthcare centre. A secondary efficacy variable was the total number of severe asthma exacerbations and the time to first and total number of exacerbations leading to hospitalisation or an emergency room visit because of asthma, requiring treatment with systemic corticosteroids. Compliance with treatment was not formally monitored to allow patient behaviour to be as close to real life as possible. Safety was evaluated by reporting serious adverse events and adverse events leading to discontinuation from the study.

Patient characteristics at baseline and run-in diary variables, which would potentially be used to predict phenotypes that would achieve a better response with higher maintenance dose, were: age, sex, body mass index, dose of ICS, smoking, exacerbations during the previous 12 months, years with asthma, ACQ-5 score, number of as-needed inhalations, days with symptoms and night-time awakenings and pre- and postbronchodilator lung function values (PEF and FEV1). These easily accessible factors were considered to be of potential use to clinicians when managing patients in a real-life setting.

The study was performed according to good clinical practice and the Declaration of Helsinki. All local ethics committees approved the study protocol. All patients gave their written informed consent for participation. The study was performed in 14 European countries.

\section{Determination of sample size}

With a sample size of 4,000 patients in each group and a significance level of $5 \%$, the study had a $90 \%$ power to detect a reduction from $10 \%$ to $7.9 \%$ (a $21 \%$ risk reduction) in the proportion of patients experiencing a severe asthma exacerbation during the 6-month study. 


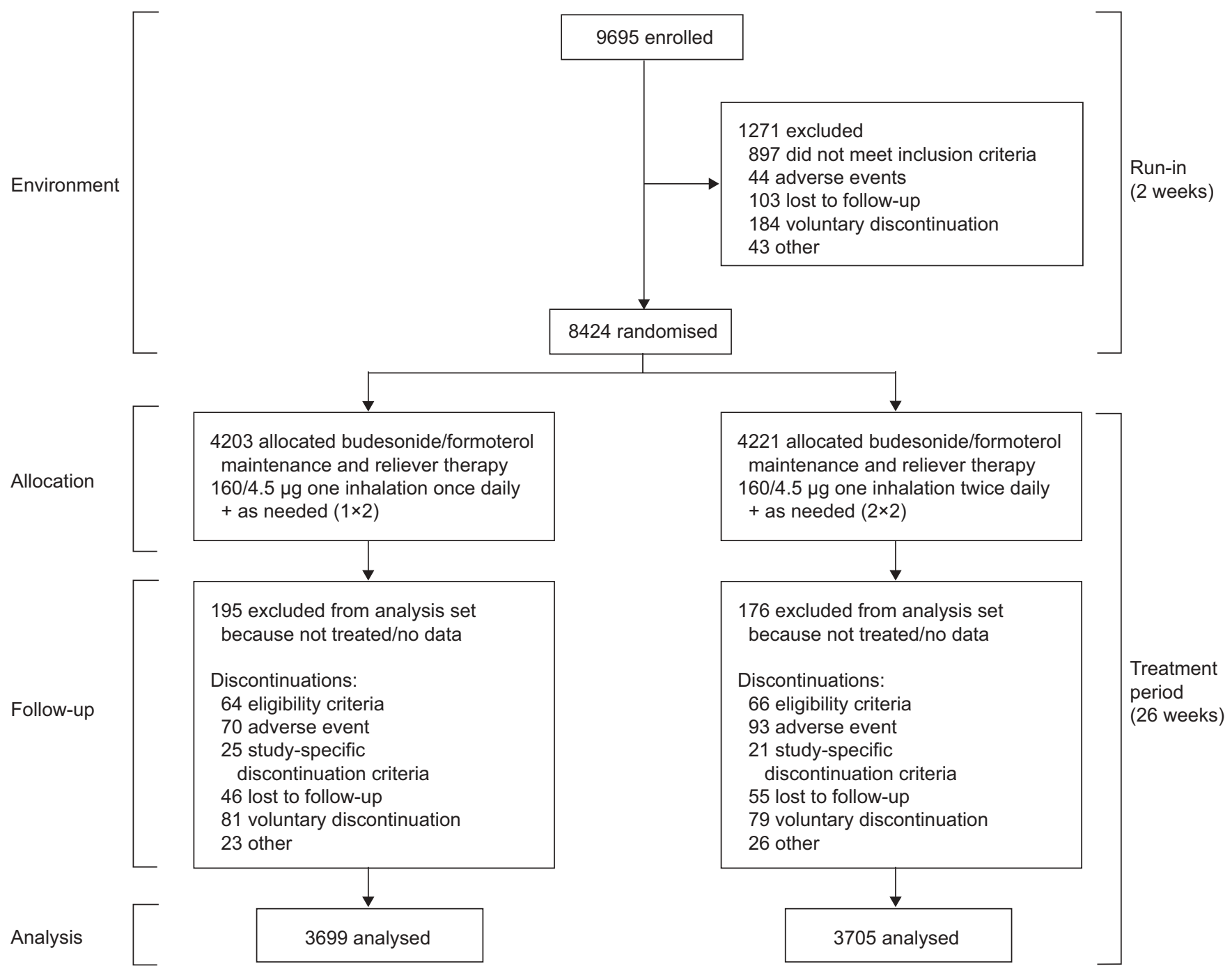

Total analysed for primary endpoint $=8053$

Total analysed for safety $=8405$

FIGURE 1. Flow chart of study design

\section{Statistical analysis}

Times to first asthma exacerbation were compared using a Cox proportional hazard model, stratified by country and with treatment as factor. The total number of exacerbations was compared between the treatments using a Poisson regression model controlling dispersion with country and treatment as factors, and total time in study as an offset variable.

Baseline predictors that could potentially identify groups of patients that benefit on $2 \times 2$ compared with $1 \times 2$ was investigated in a Cox regression model in two ways; a univariate approach and a multivariate backward selection approach. Both calculations were based on the total randomised population.

The change in ACQ-5 scores, day-time symptoms, awakenings and lung function were analysed using an ANCOVA model with treatment and country as factors and baseline value as covariate.

\section{RESULTS}

A total of 9,695 patients were enrolled and 8,424 randomised. A flow chart of study design is shown in figure 1 . Baseline characteristics of the randomised study population are shown in table 1 . There were 1,239 patients $>65$ yrs of age $(15.4 \%$ of the study population) and $11 \%$ were current smokers, with a mean smoking history of 5.7 pack-yrs. Mean duration of asthma since diagnosis was 15.5 yrs. A total of $92 \%$ of the patients in both groups completed the 6-month study.

\section{Exacerbations}

Time to first severe asthma exacerbation (the primary variable) was prolonged in the $2 \times 2$ group by $18 \%$ versus the $1 \times 2$ group (hazard ratio $0.82 ; \mathrm{p}=0.03$ ) (fig. 2 ). Before the study, the patients had a self-reported history of 145 exacerbations per 100 patients per yr. During the 6-month study, there were 322 exacerbations in 264 patients in the $1 \times 2$ group and 266 exacerbations in 219 patients in the $2 \times 2$ group, corresponding 


\begin{tabular}{|c|c|c|}
\hline $\begin{array}{l}\text { TABLE } 1 \text { Baseline charact } \\
\text { population }\end{array}$ & tics of the & nised study \\
\hline \multirow[t]{2}{*}{ Characteristics } & \multicolumn{2}{|c|}{$\begin{array}{c}\text { Budesonide/formoterol } \\
160 / 4.5 \mu \mathrm{g}\end{array}$} \\
\hline & $1 \times 2$ & $2 \times 2$ \\
\hline Subjects n & 4008 & 4045 \\
\hline Females \% & 62 & 62 \\
\hline Mean age (range) yrs & $48(18-96)$ & $48(18-90)$ \\
\hline Mean FEV 1 \% pred & 85 & 85 \\
\hline Mean reversibility \% & 6 & 6 \\
\hline Mean ICS dose at entry ${ }^{\#} \mu \mathrm{g} \cdot$ day $^{-1}$ & 1046 & 1037 \\
\hline LABA use $\%$ patients & 78 & 77 \\
\hline Mean SABA use inhalations day ${ }^{-1}$ & 1.5 & 1.5 \\
\hline Mean patients with awakenings $\%$ & 42 & 43 \\
\hline ACQ- $5>1.5 \%$ of patients & 61 & 61 \\
\hline $\mathrm{BMI} \mathbf{k g} \cdot \mathrm{m}^{-2}$ & 27.4 & 27.4 \\
\hline \multicolumn{3}{|c|}{$\begin{array}{l}1 \times 2 \text { : one dose b.i.d.; } 2 \times 2 \text { : two doses b.i.d.; FEV1: forced expiratory volume in } \\
1 \text { s; \% pred: \% predicted; ICS: inhaled corticosteroids; LABA: long-acting } \beta_{2} \\
\text { agonist; SABA: short-acting } \beta_{2} \text {-agonist; ACQ-5: five-question Asthma Control } \\
\text { Questionnaire; BMI: body mass index. \#: expressed as beclomethasone } \\
\text { dipropionate equivalent doses. }\end{array}$} \\
\hline
\end{tabular}

to a $18 \%$ difference in the total number of exacerbations $(p=0.0176)$. This translates to an incidence of 9.7 exacerbations in the $1 \times 2$ group and 8.0 exacerbations in the $2 \times 2$ group per 100 patients, i.e. 19.4 and 15.9 exacerbations per 100 patients per yr. Few exacerbations leading to hospitalisation were reported: 48 in the $1 \times 2$ and 37 in the $2 \times 2$ group (difference not significant). The vast majority of all exacerbations (95\%) were managed with oral corticosteroids without hospital admission.

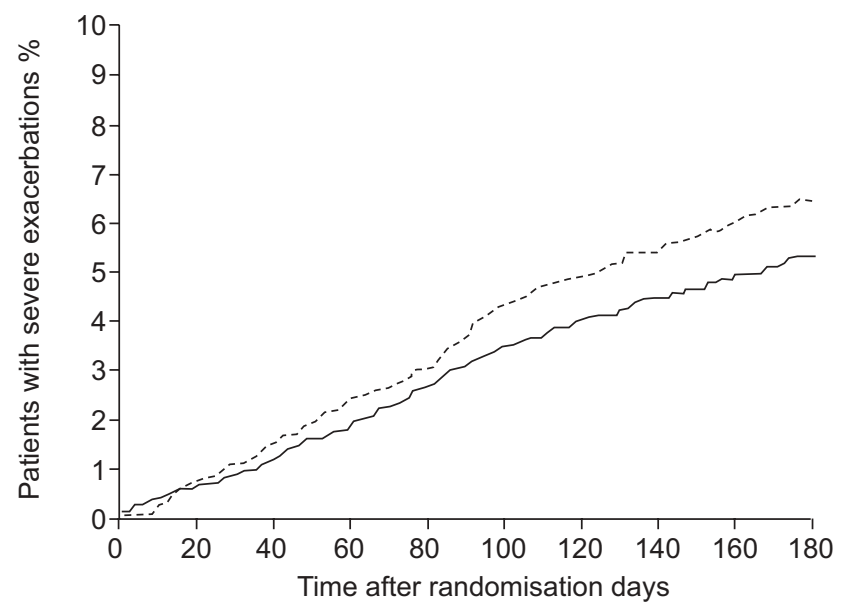

FIGURE 2. Time to first severe asthma exacerbation. An $18 \%$ (95\% Cl 1.931.5) reduction was seen with the $2 \times 2$ dose (two doses b.i.d. of $160 / 4.5 \mu \mathrm{g}$ budenoside/formoterol; - ) versus the $1 \times 2$ doses (one dose b.i.d. of $160 / 4.5 \mu \mathrm{g}$ budenoside/formoterol; ---) (hazard ratio 0.82, 95\% Cl 0.685-0.981; p=0.030). 264 patients had exacerbations under the $1 \times 2$ regimen versus 219 under $2 \times 2$.

\section{Use of medication}

The patients in the $1 \times 2$ group used a mean total of $463 \mu \mathrm{g} \cdot$ day $^{-1}$ budesonide $(318 \mu \mathrm{g}$ as maintenance and $145 \mu \mathrm{g}$ as reliever medication). The patients in the $2 \times 2$ group used a mean total of $737 \mu \mathrm{g} \cdot$ day $^{-1}(635 \mu \mathrm{g}$ as maintenance and $102 \mu \mathrm{g}$ as reliever medication). In total, 0.91 and 0.64 inhalations $\cdot$ day $^{-1}$ of reliever medication were used in the $1 \times 2$ and $2 \times 2$ groups respectively ( $\mathrm{p}<0.001$ between groups).

\section{Asthma Control Questionnaire}

At baseline, $61 \%$ of the patients had an ACQ-5 score $>1.5$, indicating poorly controlled asthma, and $12 \%$ had a score $<0.75$, indicating well controlled asthma. During treatment, there was a gradual decrease in ACQ-5 scores over time (fig. 3). The difference between the $1 \times 2$ and $2 \times 2$ groups was statistically significant $(\mathrm{p}<0.001)$ but clinically not important (a mean difference of 0.1 points).

During the study, the number of patients with poorly controlled asthma decreased from $61 \%$ to $30 \%$ and $27 \%$ for $1 \times 2$ and $2 \times 2$, respectively, while the number of patients with well-controlled asthma simultaneously increased from $12 \%$ to $42 \%$ and $47 \%$ at the end of the study. The clinically relevant changes of $>0.5$ points in ACQ- 5 are illustrated in figure 4 . In the $1 \times 2$ group, $51 \%$ of the patients reported an improvement, compared with $56 \%$ in the $2 \times 2$ group. This difference in score changes was statistically significant $(p<0.001)$.

\section{Daytime asthma symptoms and night-time awakenings}

The number of days per week with symptoms was reduced in both treatment groups, from 4.38 to 2.8 in the $1 \times 2$ group and from 4.39 to 2.3 in the $2 \times 2$ group $(\mathrm{p}<0.0001$ for $2 \times 2$ versus $1 \times 2)$. The number of night-time awakenings per week was reduced during treatment, from 1.10 to 0.65 in the $1 \times 2$ group and from 1.15 to 0.58 in the $2 \times 2$ group $(p<0.001$ for $2 \times 2$ versus $1 \times 2)$.

\section{Lung function}

A total of $99 \%$ of the patients had baseline PEF values recorded. Two-thirds of them had baseline post-bronchodilator

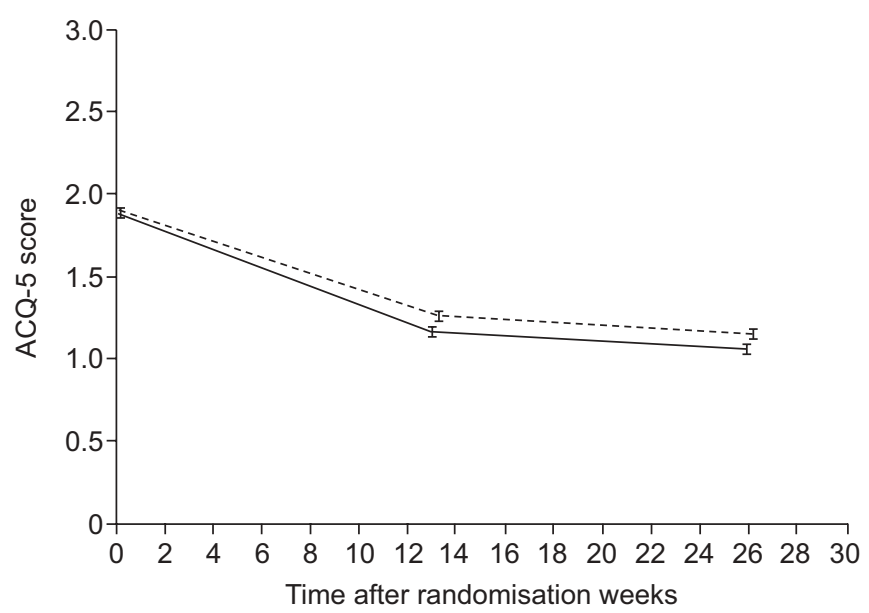

FIGURE 3. Mean five-question Asthma Control Questionnaire (ACQ-5) scores $(95 \% \mathrm{Cl}$ ) versus time in patients treated with $1 \times 2$ (one dose b.i.d.; ---) or $2 \times 2$ (two doses b.i.d.; -) of 160/4.5 $\mu \mathrm{g}$ budesonide/formoterol. The difference between the treatments was $0.097(p<0.001)$. 


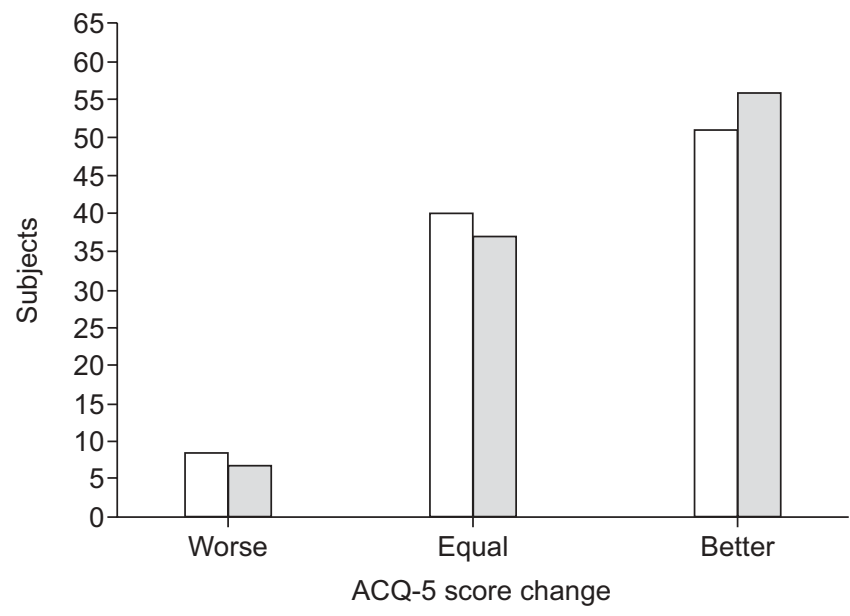

FIGURE 4. Clinically important shifts (change of $>0.5$ points) from baseline to treatment in five-question Asthma Control Questionnaire (ACQ-5) scores in patients treated with $1 \times 2$ (one dose b.i.d.; $\square$ ) or $2 \times 2$ (two doses b.i.d.; $\square$ ) of $160 / 4.5 \mu \mathrm{g}$ budesonide/formoterol $(p<0.001)$

PEF values $\geqslant 80 \%$ predicted normal $(\mathrm{PN})$. During treatment, mean pre-bronchodilator PEF improved by $16.7 \mathrm{~L} \cdot \mathrm{min}^{-1}(1 \times 2)$ and $19.4 \mathrm{~L} \cdot \mathrm{min}^{-1}(2 \times 2)$ and post-bronchodilator mean values by $9.3 \mathrm{~L} \cdot \mathrm{min}^{-1}(1 \times 2)$ and $11.8 \mathrm{~L} \cdot \mathrm{min}^{-1}(2 \times 2)$. The differences in improvements between the groups were not statistically significant $(p=0.145$ and 0.159 , respectively). FEV1 was measured in $75 \%$ of the study population. The increase in pre-bronchodilator FEV1, was $0.092 \mathrm{~L}(1 \times 2)$ and $0.129 \mathrm{~L}(2 \times 2)$ and in post-bronchodilator FEV1 $0.059 \mathrm{~L}(1 \times 2)$ and $0.086 \mathrm{~L}$ $(2 \times 2)$. The difference in change between the $1 \times 2$ and $2 \times 2$ doses was statistically significant for both pre- and postbronchodilator FEV1 $(\mathrm{p}<0.001)$.

\section{Predictor of response to the higher maintenance dose}

The results when analysing patients' baseline characteristics in relation to the difference in time to first severe asthma exacerbation (primary efficacy variable) between $1 \times 2$ and $2 \times 2$ are shown in table 2 . The only statistically significant single predictors of a better response to $2 \times 2$ were pre- and post-bronchodilator PEF. PEF post-bronchodilation came out as the strongest predictor for dose selection with both univariate and multivariate backward selection approaches (data shown only for the univariate analysis). A cut-off point of PEF post-bronchodilation of $80 \%$ PN was selected based on a spline analysis and Global Initiative for Asthma guidelines [17]. In the group with a post-bronchodilator PEF $<80 \% \mathrm{PN}$, the number of exacerbations in the $2 \times 2$ group was reduced by $26 \%$ compared with $1 \times 2$, whereas in the group with a postbronchodilator $\mathrm{PEF} \geqslant 80 \% \mathrm{PN}$, a nonsignificant reduction in number of exacerbations of $18 \%$ between the groups was seen (fig. 5). Although not statistically significant, the next best predictor of a better response to $2 \times 2$ was the post-bronchodilator FEV1 (table 2). In the group of patients $(n=5,995)$ with both FEV1 and PEF available, it was shown that both postbronchodilator FEV1 and PEF were significantly predictive of a better response to $2 \times 2(\mathrm{p}=0.0122$ and 0.0028 , respectively). Thus, lung function variables were better predictors than any other baseline variables in the study for a better response to $2 \times 2$.

\begin{tabular}{llc}
\hline TABLE 2 & $\begin{array}{l}\text { Analysis of patients' baseline characteristics in } \\
\text { relation to the difference in time to first severe } \\
\text { asthma exacerbation }\end{array}$ \\
\hline Parameter & p-value \\
\hline PEF \% PN after bronchodilation & \\
PEF \% PN before bronchodilation & 0.01 \\
FEV $1 \%$ PN after bronchodilation & 0.03 \\
FEV $1 \%$ PN before bronchodilation & 0.07 \\
Smoking & 0.20 \\
ICS baseline dose & 0.26 \\
ICS above/below 1,000 $\mu$ g.day ${ }^{-1}$ at baseline & 0.30 \\
BMI kg m $^{-2}$ & 0.40 \\
Sex & 0.38 \\
Awakenings & 0.44 \\
ACQ-5 & 0.45 \\
Exacerbations 1 yr before & 0.47 \\
Number of as-needed inhalations & 0.50 \\
Time with asthma yrs & 0.61 \\
Day-time symptoms & 0.77 \\
Age yrs & 0.86 \\
\hline
\end{tabular}

PEF: peak expiratory flow; PN: predicted normal; FEV1: forced expiratory volume in $1 \mathrm{~s}$; ICS: inhaled corticosteroids; BMI: body mass index; ACQ-5: fivequestion Asthma Control Questionnaire.

\section{Safety}

Two deaths were reported in the $1 \times 2$ group; one intracranial haemorrhage, the other unknown. In the $2 \times 2$, group one death due to colon cancer and one death due to colon cancer plus acute heart failure were reported. $\sim 2 \%$ of the patients in both groups experienced a serious adverse event. The most common serious adverse event was deterioration of asthma,

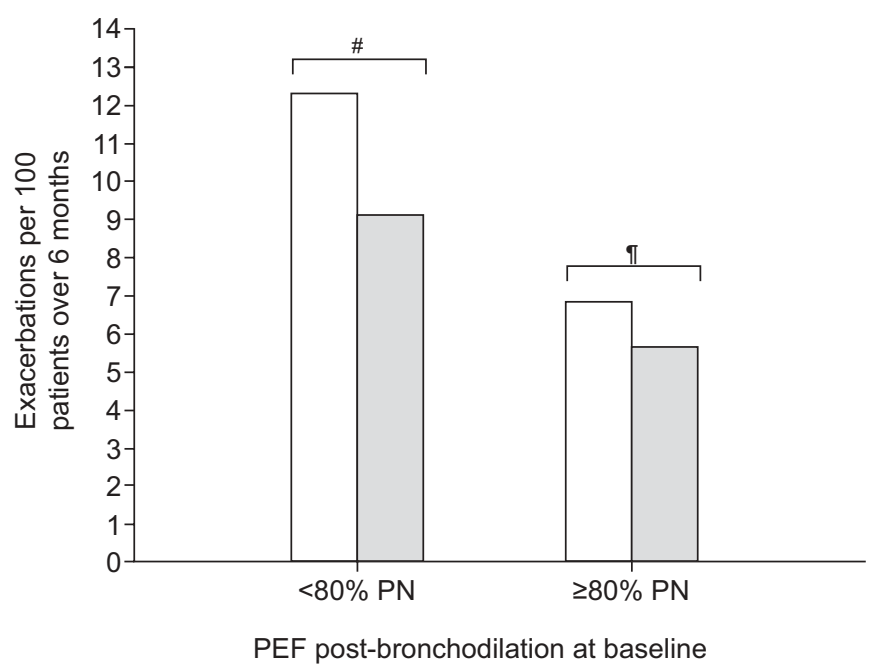

FIGURE 5. Exacerbation frequency in patients with baseline post-bronchodilator peak expiratory flow (PEF) $<80 \%$ and $\geqslant 80 \%$ predicted normal $(\mathrm{PN})$ treated with $1 \times 2$ (one dose b.i.d.; $\square$ ) or $2 \times 2$ (two doses b.i.d.; $\square$ ) of $160 / 4.5 \mu \mathrm{g}$ budesonide/formoterol. ${ }^{*}: p<0.033$. ${ }^{\natural}: p<0.077$. 
which occurred in 13 and nine patients in the $1 \times 2$ and $2 \times 2$ groups, respectively.

There was no significant difference between the groups regarding time to discontinuation because of adverse events $(1 \times 2$ versus $2 \times 2 ; \mathrm{p}=0.40)$. Worsening of asthma was the most frequent reason for discontinuation, 20 and 11 patients in the $1 \times 2$ and $2 \times 2$ groups, respectively.

\section{DISCUSSION}

The aim of this study was to compare two maintenance doses within the budesonide/formoterol maintenance and reliever therapy concept. We compared the standard maintenance dose, $160 / 4.5 \mu \mathrm{g} 1 \times 2$, with the highest approved dose, $2 \times 2$ [1, 2]. The higher maintenance dose prolonged the time to first severe exacerbation by $18 \%$ compared with $1 \times 2$. This difference was significant with a p-value just below 0.05 , showing that the power calculation of the study was appropriate. The rate of severe exacerbations decreased to 15 and 19 exacerbations per 100 patients per yr with $2 \times 2$ and $1 \times 2$ maintenance doses, respectively, and these figures were lower than the figures in previously reported budesonide/formoterol maintenance and reliever therapy studies with identical maintenance doses, i.e. 19 [7] and 24 [9] exacerbations per 100 patients per yr with $1 \times 2$, and 24 [9] and 25 [10] with $2 \times 2$. With salmeterol/fluticasone, and a SABA as reliever, the corresponding exacerbation figures were 31-38 per 100 patients per yr [8-10]. Not unexpectedly, the as-needed ICS use was somewhat higher in the $1 \times 2$ group than in the $2 \times 2$ group, although importantly the total daily glucocorticoid drug load was much lower in the $1 \times 2$ group. No clinically important differences between the $1 \times 2$ and $2 \times 2$ groups were seen in changes in ACQ-5 scores, day- and night-time symptoms or in lung function values. In both treatment groups, the changes from baseline in these asthma control variables were of the same or greater magnitude compared with previous budesonide/formoterol maintenance and reliever therapy studies [7-10].

No safety concerns were raised in the study, which is in line with the results of other budesonide/formoterol maintenance and reliever therapy studies [18]. We could conclude that the higher $2 \times 2$ maintenance dose was superior and this dose should normally be of no concern from a safety point of view [18]. However, in most countries, $1 \times 2$ is considered the standard maintenance dose and both patients and clinicians hold concerns about intake of high doses of ICS if not deemed necessary. Therefore, we investigated what baseline factors might predict a better response to $2 \times 2$ and hypothesised that smoking, a history of exacerbations, a longer duration of asthma, a higher ICS dose and poor asthma control might be the most relevant predictors. However, none of the postulated factors were predictors of a better response to $2 \times 2$. Instead, baseline pre- and post-bronchodilator PEF were the only statistically significant predictors of a better response to $2 \times 2$. FEV1 post-bronchodilation showed a similar trend in the analysis of the total population and, in the subgroup of patients with both FEV1 and PEF available, FEV1 postbronchodilation was shown to be a statistically significant in predicting response to a higher maintenance dose. For patients with a post-bronchodilator PEF value $\geqslant 80 \%$ PN, comprising two-thirds of the population in this study, the maintenance dose of budesonide/formoterol did not significantly affect the risk of having an exacerbation. It was unexpected that a low PEF value was the only variable predicting a better response to $2 \times 2$. Plausible explanations include differences in airway inflammation and lung deposition of ICS between the groups and in formoterol doses. It could be that, due to the more severe airway obstruction in patients with low lung function compared with the rest of the study population, the lung deposition is impaired and, therefore, a higher lung dose may result in a better response [19]. It could also be that patients with poorer lung function have a more severe inflammatory process in their airways and therefore require a higher ICS dose. Contrary to this hypothesis, however, is the observation that patients with a high baseline dose of ICS did not behave differently when randomised to $1 \times 2$ compared with $2 \times 2$, indicating that treatment with a high ICS dose may not necessarily reflect asthma severity and, also, that overtreatment with ICS at baseline cannot be excluded. Regarding the effects of the formoterol doses, the patients with a lower PEF had, of course, more room for improvements in lung function; thus, a higher bronchodilator dose might have been of clinical importance.

The ACQ- 5 scores showed that only $12 \%$ of the patients had well-controlled asthma at baseline (ACQ-5 $<0.75$ ). The clinically relevant improvements in ACQ-5 scores, e.g. changes of $>0.5$ scores during the study, were quite clear in both groups. The proportion of patients with a score $<0.75$ increased and the proportion of patients with scores $>1.5$ decreased, with a statistically significant but clinically unimportant mean difference of a 0.1-point change between the two groups. Only a $5 \%$ difference in the proportion of patients reporting improvement in their asthma was seen.

We found that the changes from baseline in ACQ-5 scores were very similar to previous controlled budesonide/formoterol maintenance and reliever studies with the $1 \times 2[7]$ and the $2 \times 2$ maintenance dose $[9,10]$. The reduction in symptom scores and awakenings were greater than in the cited studies [7-10] and, similarly, the reduction in use of reliever medication [7-10].

Our study indicates that most patients benefit from the standard dose of budesonide/formoterol. Considering the outcomes in the study with the lower corticosteroid load and the lower costs with the $1 \times 2$ dose [20,21], it seems appropriate to recommend this dose for initial use and to increase the maintenance dose to $2 \times 2$ in patients not fully controlled by this standard dose. This treatment approach would be particularly warranted in patients with persistent low lung function despite the standard maintenance dose.

We conclude that in a real-life setting, budesonide/formoterol maintenance and reliever therapy at the $2 \times 2$ maintenance dose did prolong time to first severe exacerbation and reduced symptoms, but at a higher medication load. Patients with low lung function benefitted most from the higher maintenance dose.

\section{SUPPORT STATEMENT}

O. Selroos drafted the manuscript, for which he received financial support from AstraZeneca. 


\section{CLINICAL TRIAL}

This study is registered at www.clinicaltrials.gov with clinical trial identifier no. NCT00463866.

\section{STATEMENT OF INTEREST}

Statements of interest for all authors can be found at www.erj. ersjournals.com $/ \mathrm{misc} /$ statements.dtl

\section{ACKNOWLEDGEMENTS}

The authors wish to thank the investigators and study nurses who randomised patients at 878 study centres in 14 countries and whose time and effort contributed greatly to the conduct of the study.

\section{REFERENCES}

1 Buhl R, Vogelmeier C. Budesonide/formoterol maintenance and reliever therapy: a new treatment approach for adult patients with asthma. Curr Med Res Opin 2007; 23: 1867-1878.

2 Selroos O. A smarter way to manage asthma with a combination product of a long-acting $\beta_{2}$-agonist and inhaled corticosteroid. Ther Clin Risk Manag 2007; 3: 349-359.

3 O'Byrne PM, Bisgaard H, Godard PP, et al. Budesonide/ formoterol combination therapy as both maintenance and reliever medication in asthma. Am J Respir Crit Care Med 2005; 171: 129-136.

4 Scicchitano R, Aalbers R, Ukena D, et al. Efficacy and safety of budesonide/formoterol single inhaler therapy versus a higher dose of budesonide in moderate to severe asthma. Curr Med Res Opin 2004; 20: 1403-1418.

5 Rabe KF, Pizzichini E, Ställberg B, et al. Budesonide/formoterol in a single inhaler for maintenance and relief in mild-to-moderate asthma. A randomized, double-blind trial. Chest 2006; 129: 246-256.

6 Bateman ED, Bantje TA, João Gomes M, et al. Combination therapy with single inhaler budesonide/formoterol compared with high dose of fluticasone propionate alone in patients with moderate persistent asthma. Am J Respir Med 2003; 2: 275-281.

7 Rabe KF, Atienza T, Larsson P, et al. Effect of budesonide in combination with formoterol for reliever therapy in asthma exacerbations: a randomised controlled, double-blind study. Lancet 2006; 368: 744-753.

8 Kuna P, Peters MJ, Manjra AI, et al. Effect of budesonide/ formoterol maintenance and reliever therapy on asthma exacerbations. Int J Clin Pract 2007; 61: 725-736.
9 Vogelmeier C, D’Urzo A, Pauwels R, et al. Budesonide/formoterol maintenance and reliever therapy: an effective asthma treatment option? Eur Respir J 2005; 26: 819-828.

10 Bousquet J, Boulet L-P, Peters MJ, et al. Budesonide/formoterol for maintenance and relief in uncontrolled asthma vs. high-dose salmeterol/fluticasone. Respir Med 2007; 101: 2437-2446.

11 Bateman ER, Boushey HA, Bousquet J, et al. Can guidelinedefined asthma control be achieved? The Gaining Optimal Asthma controL study. Am J Respir Crit Care Med 2004; 170: 836-844.

12 Lundborg M, Wille S, Bjermer L, et al. Maintenance plus reliever budesonide/formoterol compared with a higher maintenance dose of budesonide/formoterol plus formoterol as reliever in asthma: an efficacy and cost-effectiveness study. Curr Med Res Opin 2006; 22: 809-821.

13 American Thoracic Society (ATS). Standards for the diagnosis and care of subjects with chronic obstructive pulmonary disease (COPD) and asthma. Am Rev Respir Dis 1987; 136: 225-244.

14 Juniper EF, O’Byrne PM, Guyatt GH, et al. Development and validation of a questionnaire to measure asthma control. Eur Respir J 1999; 14: 902-907.

15 Svensson K, Mörk AC, Juniper EF. ACQ. Is five out of seven items acceptable in large clinical studies? Qual Life Res 2003; 12: 771.

16 Juniper EF, Bousquet J, Abetz L, et al. Identifying "wellcontrolled" and "not well-controlled" asthma using the Asthma Control Questionnaire. Respir Med 2006; 100: 616-621.

17 Global Initiative for Asthma. GINA Report: global strategy for asthma management and prevention. www.ginasthma.com/ download.asp?intld=343 Date last accessed: December 16, 2009. Last updated 2009.

18 Sears MR, Radner F. Safety of budesonide/formoterol maintenance and reliever therapy in asthma trials. Respir Med 2009; 103 1960-1968.

19 Schreurs AJ, Sinninghe Damste HE, de Graaff CS, et al. A doseresponse study with formoterol Turbuhaler ${ }^{\circledR}$ as maintenance therapy in asthmatic patients. Eur Respir J 1996; 9: 1678-1683.

20 Price D, Wirén A, Kuna P. Cost-effectiveness of budesonide/ formoterol maintenance and reliever asthma therapy. Allergy 2007; 62: 1189-1198.

21 Ställberg B, Ekström T, Neij F, et al. A real-life cost-effectiveness evaluation of budesonide/formoterol maintenance and reliever therapy in asthma. Respir Med 2008; 102: 1360-1370. 